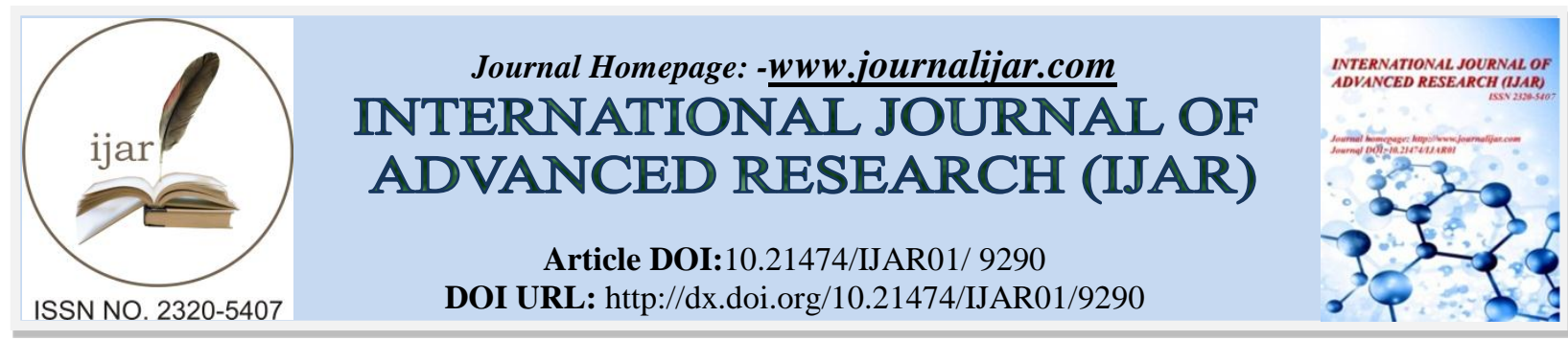

RESEARCH ARTICLE

\title{
OPTIMIZATION OF THE SIZING OF HYBRID WIND, SOLAR PHOTOVOLTAIC, BIODIESEL AND STORAGE SYSTEMS USING THE INTEGER LINEAR PROGRAMMING METHOD.
}

Amy Nabiliou ${ }^{1}$, Koffi Mawugno Kodjo ${ }^{2}$, Komi Amoussou ${ }^{1}$ and Ayité Sénah Akoda Ajavon ${ }^{2}$.

1. Electrical Engineering Department, Ecole Nationale Supérieure d'Ingénieurs (ENSI), University of Lome, Togo.

2. LAboratoire de Recherche en Sciences de l'Ingénieur (LARSI), Ecole Nationale Supérieure d'Ingénieurs (ENSI), University of Lome, Togo.

\section{Manuscript Info}

(..........................

Manuscript History

Received: 15 April 2019

Final Accepted: 17 May 2019

Published: June 2019

Key words:-

Hybrid Energy System, Optimization,

Sizing, Integer Linear Programming (ILP).

\begin{abstract}
This article presents a program for optimizing the sizing of hybrid energy systems, composed of wind turbines, photovoltaic modules and biodiesel generators, with battery storage, for the electrification of isolated sites. Technical-economic optimization is obtained using the integer linear programming (ILP) method. In order to validate and demonstrate the performance of the model developed and programmed in python language, a comparative analysis is performed by doing the same sizing with the HOMER software. The simulations have given, for an isolated site around the city of Lomé in Togo whose peak amounts to $65 \mathrm{~kW}$ : 162 photovoltaic modules of $340 \mathrm{~W}$ each, 152 batteries of $1 \mathrm{kWh}, 1$ biodiesel generator of $100 \mathrm{~kW}$ which has a duration of use of $1200 \mathrm{~h} /$ year and a bidirectional converter of $52 \mathrm{~kW}$. The total net cost of the sizing obtained by ILP is $\$ 871,095.29$. The same simulations made in HOMER gave us a power of $60.9 \mathrm{kWp}$ for solar photovoltaic (180 modules), 83 batteries, 1 biodiesel generator with a duration of use of $3114 \mathrm{~h} /$ year and a $48 \mathrm{~kW}$ converter. Sizing HOMER returns a total net cost of $\$ 898,372$. This slight difference in the results relative to costs, which is only around 3\%, validates the accuracy of the implemented model.
\end{abstract}

Copy Right, IJAR, 2019,. All rights reserved.

\section{Introduction:-}

Energy is one of the crucial factors of socio-economic development. Faced with its ever-increasing demand, the use of renewable energy sources appears as a solution for a greener world. Because of their intermittency and their potential varying from one region to another, they are hybridized with conventional sources of production.

In general, these systems require the use of storage means that ensure continuity of service and improve the quality of the energy produced. The use of hybrid renewable energy systems in isolated sites has become an interesting solution for areas where the extension of the electricity grid is not feasible, or requires a relatively high cost which consequently requires technical-economic optimization. (HOMER, 2017)

Corresponding Author:-Amy Nabiliou.

Address:-Electrical Engineering Department, Ecole Nationale Supérieure d'Ingénieurs (ENSI), University of Lome, Togo. 
In addition, the ecological constraints due to global warming, leading to all the undesirable phenomena of climate change, require us to take an exploratory step in this direction so that our electricity production systems meet the desired ecological standards.

In the literature, we can find two methods used for the combination of renewable energies including (wind and photovoltaic) in the electrical networks, the deterministic method which is based on the analysis of a reduced quantity of positions estimated a priori as uncertain for which one examines the behavior of the electrical system and the probabilistic method which considers all the possible cases with their probability of circumstance in order to appreciate the danger of not respecting a constraint of the system (Seydou Ouedraogo and al., 2015; KANSARA B. and PAREKH B.R, 2011 ). It should be noted that currently, connection studies are based on deterministic cases by introducing a probabilistic determination of the means of production and consumption.

The optimization of hybrid renewable energy systems involves modeling the various energy sources of the system, defining the various technical and economic constraints of the system and the objective function of minimizing the total cost of the system. This leads to a mathematical model whose resolution leads to the sizing of the system.

\section{Methodology:-}

The sizing of the installation to be studied will be organized as follows: the definition of the optimization method adopted, the modeling of all the production sources of the hybrid system and the explanation of the objective function reflecting the economic optimization.

\section{Definition of the optimization method:-}

Integer Linear Programming (ILP) is a field of mathematics and theoretical computer science in which problems of optimization of a particular form are considered. These problems are described by a cost function with linear constraints and integer variables (LIBERTI L. and RUSLAN S., 2006).

An integer linear program corresponds to a system of linear equations and inequations (constraints) whose unknowns are positive or zero integer values and the coefficients are integers, with a function to be optimized (minimize), which is linear to real coefficients. An integer linear optimization program can be in matrix form according to the following formulation (BOUHARCHOUCHE A. and al., 2013):

Either a matrix $A=\left(\begin{array}{ccc}a_{11} & \cdots & a_{1 j} \\ \vdots & \ddots & \vdots \\ a_{i 1} & \cdots & a_{i j}\end{array}\right) \in M_{i, j}(\mathbb{Z})$, and a column vector $B=\left(\begin{array}{c}b_{1} \\ \vdots \\ b_{i}\end{array}\right) \in M_{i, 1}(\mathbb{Z})$ and a tuple $\left(c_{1}, \ldots, c_{j}\right) \in \mathbb{R}^{m}$; find a solution $\left(x_{1}, \ldots, x_{j}\right) \in \mathbb{N}^{m}$ satisfying $A\left(\begin{array}{c}x_{1} \\ \vdots \\ x_{j}\end{array}\right)=\left(\begin{array}{c}b_{1} \\ \vdots \\ b_{i}\end{array}\right)$ which minimizes the cost function (objective) $c\left(x_{1}, \ldots, x_{j}\right)=\sum_{j=1}^{n} c_{j} x_{j}$.

Values $x_{j}$ are the decision variables to which negativity constraints are applied; $c_{j}, a_{i j}$ and $b_{i}$ are constants whose different equations (inequalities) constitute the linear constraints. The determination of all the constants and decision variables is done by considering the energy consumption of the site and the modeling of the various energy generators of the system.

\section{Architecture of the Hybrid Energy System:-}

The hybrid energy system to be sized consists of photovoltaic panels, wind turbines, biodiesel generators and a battery storage system. Figure 1 shows the configuration of the power generation system and the connection of the generators to the different buses.

The system consists of two connection bus: AC and DC. The photovoltaic panels and the storage system are connected to the DC bus. Wind turbines and generators producing alternating current and voltage are connected to the AC bus. The two bus are connected via a bidirectional AC / DC converter. All loads at the isolated site are connected to the AC bus assuming that all electrical equipment is $\mathrm{AC}$ powered and that all non-AC equipment has its own transformer-rectifier. 


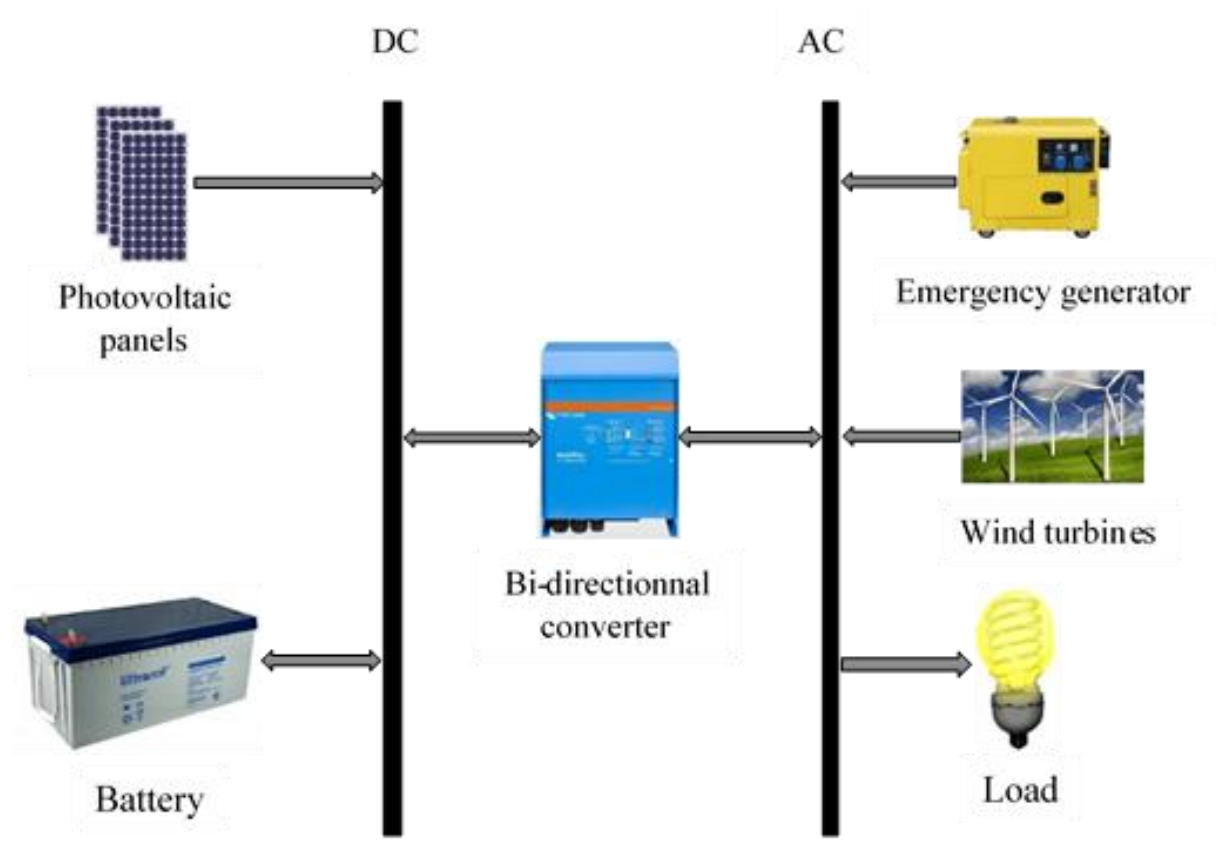

Figure 1:-Configuration of the Hybrid Energy System

Modeling and sizing of different energy sources:-

Any sizing of a hybrid system is required to satisfy the energy demand at each moment of the site. As the latter varies over time, it must be covered by a combination of different energy sources.

\section{Requested power $\mathbf{P}_{\mathrm{d}}(\mathbf{t})$ :-}

The power required at a given time (relation 1) corresponds to the sum of all the powers of the electrical loads to be supplied on the site at that time. It leads to the first constraint, which is the response to demand.

$t \epsilon T, P_{d}(t)+P_{e}(t)=P_{P V}(t)+P_{W}(t)+P_{g}(t)+P_{b}(t)$

where at a given time $t$ considered, $P_{W}(t) \geq 0$ is the wind power which depends on the wind speed and the number of wind turbines installed, $P_{P V}(t) \geq 0$ is the power of the photovoltaic field depending on the torque (irradiance, temperature) and the number of photovoltaic modules installed, $P_{g}(t) \geq 0$ is the power of biodiesel generators according to the number of generators in operation, $P_{b}(t)$ is the power exchanged between the batteries and the whole system depending on the number of batteries installed and $P_{e}(t) \geq 0$ is the excess power that cannot be stored and will therefore have to be evacuated.

\section{Modeling and sizing of the photovoltaic generator:-}

The single diode model is the most classic model. It uses a current generator for modelling the incident light flux, a diode for cell polarization phenomena, two resistors (series and shunt) for losses (Figure 2).

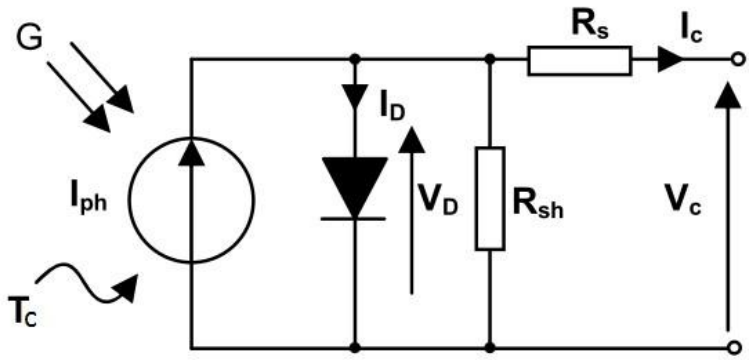

Figure 1:-Single diode model of a photovoltaic cell. 
This model has four variables. The two input variables are the irradiance in the plane of the modules $\left(\mathrm{W} / \mathrm{m}^{2}\right)$ and the junction temperature of the cell $\left({ }^{\circ} \mathrm{C}\right)$. The two output variables are the current $(\mathrm{A})$ and the voltage $(\mathrm{V})$ provided by the group of cells.

This model allows us to calculate by equation (2) the instantaneous power produced by the modules from the temperature and irradiance data.

$P_{P V}(t)=N_{P V} \times \eta_{P V} \times G(t) \times A_{e f f}$

Where $N_{P V}$ (integer value) is the number of photovoltaic modules to be installed, $G(t)\left(\mathrm{W} / \mathrm{m}^{2}\right)$ is the irradiation at time $\mathrm{t}, A_{\text {eff }}\left(\mathrm{m}^{2}\right)$ represents the module surface and $\eta_{P V}$ is the efficiency characterizing the photo-electron conversion rate of the module given by the relation (3):

$\eta_{P V}=\eta_{r} \times \eta_{p c} \times\left(1-\beta \times\left(T_{c}-T_{c r e f}\right)\right)$

In this equation, $\eta_{r}$ is the reference efficiency of the photovoltaic module and $\eta_{p c}$ represents the efficiency characterizing the influence of the load, the latter is equal to 1 in the case where the photovoltaic system operates in MPPT (Maximum Power Point Tracking) mode. $\beta$ is the assumed constant temperature coefficient of the photovoltaic module, the cell reference temperature is represented by $T_{\text {cref }}\left({ }^{\circ} \mathrm{C}\right)$, similarly, $T_{c}(\mathrm{t})$ is the cell temperature given by the relationship (4) :

$T_{c}(t)=T_{a}+\left(\frac{T_{\text {noct }}-T_{a_{\text {noct }}}}{G_{\text {noct }}}\right) \times G(t)$

$T_{a}\left({ }^{\circ} \mathrm{C}\right)$ is the ambient temperature, $T_{\text {noct }}\left({ }^{\circ} \mathrm{C}\right)$ represents the temperature of the cells under NOCT (Normal Operating Cell Temperature) conditions: $G_{n o c t}=800 \mathrm{~W} / \mathrm{m} 2, T_{a_{\text {noct }}}=20^{\circ} \mathrm{C}$, Spectrum AM=1.5) (BOUHARCHOUCHE A. and al., 2014).

Modeling and sizing of the wind farm:-

Wind speed is the main parameter in the production of electricity by wind turbines. The power characteristic of a wind turbine has four zones (Figure 3): Zone I, where the power produced is zero, Zone II, where the power supplied to the shaft depends on the wind speed V, Zone III, where the speed of rotation is generally kept constant by a regulating device and where the power supplied remains substantially equal to the rated power, and Zone IV, where the operational safety system stops the rotation and transfer of energy (KODJO K. M., 2005).

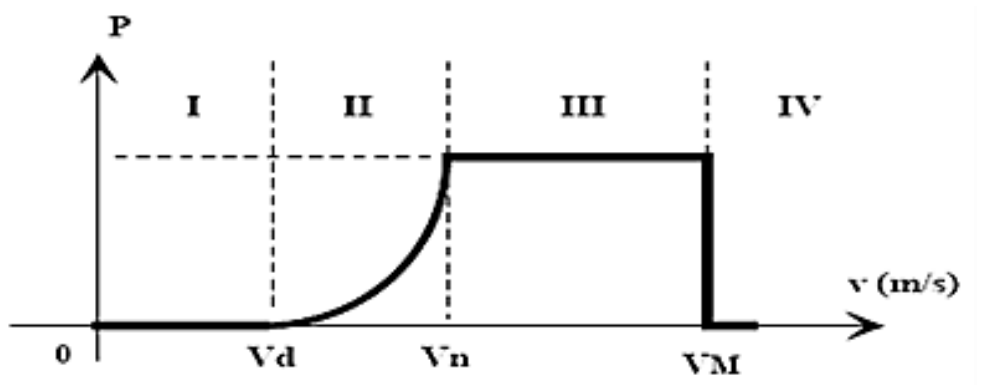

Figure 3:-Diagram of the useful power on the shaft according to wind speed.

A simple model can simulate the output power of the given wind farm as shown in the relation (5):

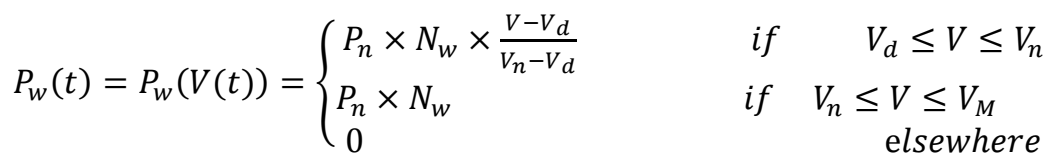

$N_{w}, P_{n}, V_{\text {dem }}, V_{n}$ and $V_{\text {max }}$ respectively represent the number of wind turbines to be installed, the rated power, the starting speed, the rated speed and the maximum speed of a wind generator. 


\section{Modeling and sizing of the biodiesel generator:-}

The type of generator chosen is the one that provides variable power according to demand. This power is closely related to consumption as modelled in Figure 4.

Fuel consumption

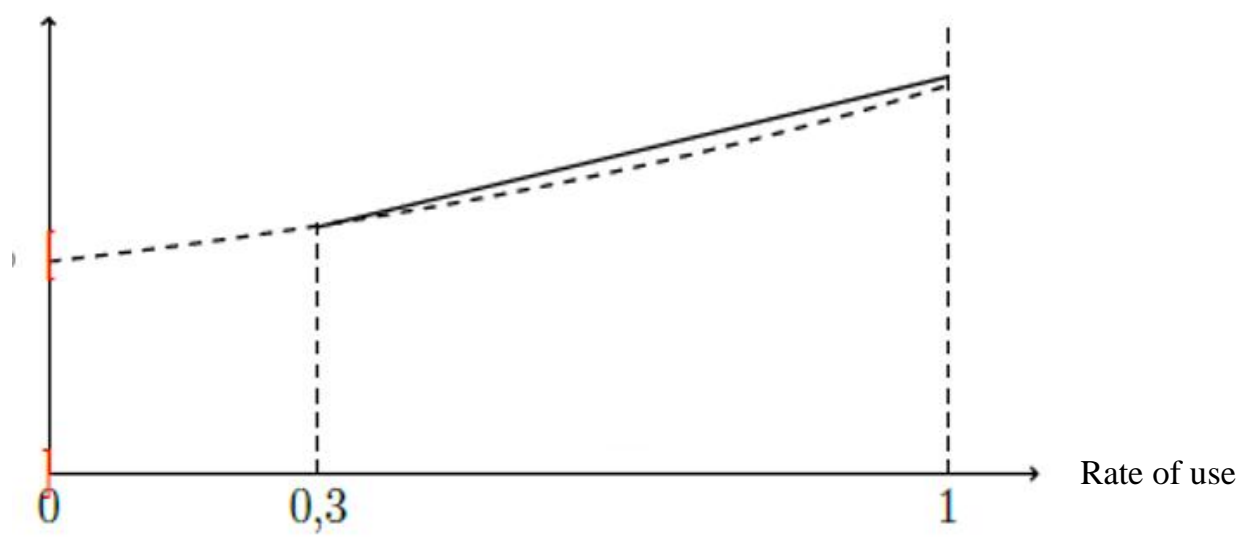

Figure 4:-Linear modelling of biodiesel generator consumption

With a slight curvature, it is often replaced by a linear interpolation corresponding to a line. The generator utilization rate must always be higher than $\mu_{g}=30 \%$ in order to avoid excessive generator wear and tear in addition to excess fuel consumption (AZIB T. and al., 2016; KASERA J., and al., 2012) The equations for generator sizing are respectively the relations (6) and (7):

$N_{g} \geq \max \left(\frac{P_{d}(t)}{P_{g M}}\right)$

$\mu_{g} \times N_{g}(t) \times P_{g M} \leq P_{g}(t) \leq N_{g}(t) \times P_{g M}$ with $N_{g}(t) \leq N_{g}$

$N_{g}$ is the number of generators potentially installed, $N_{g}(t)$ the number of generators started at a time $t$ and $P_{g M}$ is the nominal power of a generator set. The relation (6) reflects the ability of groups to satisfy all demand in the event of total unavailability of other sources in the system.

\section{Sizing of energy storage by battery:-}

Storage capacity is the maximum amount of energy that can be stored in the batteries. It depends on the maximum energy $E_{b M}$ and the number of batteries installed $N_{b}$ which is an integer variable. A battery cannot be charged or discharged at any power only because of its own characteristics $P_{b d M}$ and $P_{b c M}$ representing respectively the maximum discharge and charging power of the batteries expressed by (8).

$N_{b} \cdot P_{b d M} \cdot d(t) \leq E_{b}(t) \leq N_{b} \cdot E_{b M}$ and $-N_{b} \cdot P_{b c M} \leq P_{b}(t) \leq \frac{d E_{b}(t)}{d t}$

The initial energy of the battery $E_{b}(0)$ must be known, (BARBIER T., 2013; BOUHARCHOUCHE A. and al., 2014; KIM S.T. and al., 2015; UMUHOZA J. and al., 2017). We can then give the constraints of the continuity of the energy in the battery by the relation (9):

$E_{b}(0)=u_{b 0} \cdot N_{b} \cdot E_{b M}$ and $E_{b}(t) \leq\left(1-e_{b p c}^{d(t)}\right) \times E_{b}(t-1)-P_{b}(t-1) \times d(t) \times e_{b}$

With $u_{b 0}$ the percentage of initial energy of the battery in relation to its maximum capacity; $0 \leq e_{b p c}^{d(t)} \leq 1$ is the pressure drop coefficient representing the percentage of energy automatically lost by the battery every hour ; $0 \leq e_{b} \leq 1$ is the charge / discharge efficiency coefficient.

\section{Sizing of the converter:-}

The converter chosen is bidirectional. It can therefore transmit energy in both directions (from the continuous bus to the alternative bus and vice versa). Its sizing amounts to finding the maximum power $P_{\text {conv }}$ passed through it. The constraint associated with the converter is relation (10):

$t \in T, P_{\text {conv }} \geq \max \left(P_{P V}(t)+P_{b}(t)\right)$

$P_{\text {conv }}$ is not time-dependent because it is a fixed value and the number of converters is 1 because only one converter is used for the whole system. 


\section{Economic optimization of the sizing:-}

The economic optimization of the sizing is achieved by minimizing the objective function that gathers all the costs of the project (relation 11):

$\min C_{\text {projet }}=\min \left\{C_{i}(S)+C_{m}(S)+C_{r}(S)+C_{j}+C_{e m}+C_{s}(S)\right\}$

\section{Initial cost of the system :-}

It corresponds to the purchase of the various elements (generators, supports, accessories), their transport and their installation and is expressed by the relation (12).

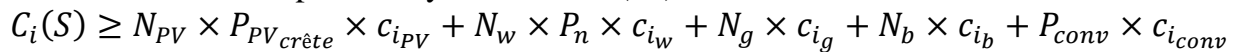

$c_{i_{P V}}, c_{i_{w}}, c_{i_{g}}, c_{i_{b}}$ and $c_{i_{c o n v}}$ are the unit costs of installing photovoltaic modules, wind turbines, generators, batteries and converter respectively. The first two costs are expressed in $\$$ per unit of installed power while the initial costs of diesel generators and batteries are expressed in \$ per item purchased (BARBIER T., 2013; BOUHARCHOUCHE A. and al., 2013).

The cost of operation and maintenance $C_{m}(S)$ :-

The maintenance cost (relation 13) corresponds to the operations of revision, renewal of consumables (oils, filters, etc.) and verification of elements.

$C_{m}(S) \geq N_{P V} \times P_{P V_{\text {crête }}} \times c_{m_{P V}}+N_{w} \times P_{n} \times c_{m_{w}}+N_{b} \times c_{m_{b}}+c_{m_{g}} \times \sum_{t \in T} N_{g}(t) . d(t)$

The maintenance costs of photovoltaic modules and wind turbines $\left(c_{m_{P V}}\right.$ and $\left.c_{m_{w}}\right)$ are expressed in $\$$ per unit of installed power and the maintenance costs of batteries in $\$$ per module. $c_{m_{g}}$ is the cost per hour of use of the generator set, multiplied by the magnitude $D_{g}=\sum_{t \in T} N_{g}(t) \cdot d(t)$ which represents the total operating time of the generators.

The cost of renewing components $C_{r_{i}}(S)$ :-

Each component $i$ of the system has a lifetime $d \vartheta_{i}$. It must be replaced periodically over the entire operating life of the hybrid system (BARBIER T., 2013; CAN H., ICKILLI D. and al., 2012; NGAN M. S. and TAN C. W., 2012 ). For any component $i$ of the hybrid system except the generator set, the expression of the component renewal cost is given by the relation (11).

$C_{r_{i}}(S) \geq N_{i} \times c_{i} \times\left\lfloor\frac{\left(d \vartheta_{S}-0,01\right)}{d \vartheta_{i}}\right\rfloor$

The magnitude $\left[\frac{\left(d \vartheta_{S}-0.01\right)}{d \vartheta_{i}}\right]$ represents the integer value rounded by default of the number $\frac{\left(d \vartheta_{S}-0,01\right)}{d \vartheta_{i}}$ and corresponds to the number of renewals of component $i, d \vartheta_{S}$ being the lifetime of the project. The lifetime of the units is in hours of use and they are not all started at the same time. The associated renewal constraints are given by the relations (15):

$N_{g} \times d \vartheta_{g}+\sum_{i=1}^{T} A_{g}(i) \times d \vartheta_{g} \geq D_{g} \times T$ and $C_{r g} \geq \sum_{y \in T} A_{g}(y) \times c_{i_{g}}$

$A_{g}(y)$ is the binary variable for purchasing generators in the corresponding year.

The cost of biodiesel fuel $C_{j}$ :-

Considering the hypothesis that the fuel consumption of the group is linear between $\mu \mathrm{g}$ and $100 \%$ of its nominal power as modelled in Figure 4, we obtain a straight line with a coefficient director $a_{g}$ and the ordinate at origin $b_{g}$. $c_{j}$ being the price per liter of fuel, the total $\operatorname{cost} C_{j}$ is given by the relation (16):

$C_{j} \geq c_{j} \times\left(a_{g} \times P_{g}(t)+b_{g} \times N_{g}(t)\right)$

The cost of polluting emissions:-

All pollutants: $\mathrm{P}=\{\mathrm{CO}, \mathrm{HC}, \mathrm{NOx}\}$ corresponds respectively to emissions of carbon monoxide, unburned hydrocarbons and derivatives of nitrogen monoxide. The cost of pollutant emissions Cem is linked to the constraint of the relation (17):

$C_{e m} \geq \sum_{p \in P} \frac{e_{m}(p) \times \sum_{t \epsilon T}\left(a_{g} \times P_{g}(t)+b_{g} \times N_{g}(t)\right)}{1000} \times c_{e m}(p)$

$e_{m}(p)$ is the amount of pollutant released $\mathrm{p}$ for each liter of fuel consumed in grams and the parameter $c_{e m}(p)$ is the cost per $\mathrm{kg}$ of pollutant $\mathrm{p}$. 
The cost of salvage of the components:-

The salvage cost (relation 18) is the price that can be recovered at the end of the project if the unamortized equipment is sold. For any component $\mathrm{i}$ of the hybrid system except the generator set (Seydou Ouedraogo and al., 2015; ENGELAND K. and al, 2017; REHMAN S. M. and al., 2012).

$C_{s_{i}}(S) \geq N_{i} \times c_{i} \times\left(1-\left(\frac{d \vartheta_{S}}{d \vartheta_{i}}-\left\lfloor\frac{\left(d \vartheta_{S}-0.01\right)}{d \vartheta_{i}}\right\rfloor\right)\right)$

The magnitude $\frac{d \vartheta_{S}}{d \vartheta_{i}}-\left\lfloor\frac{\left(d \vartheta_{S}-0.01\right)}{d \vartheta_{i}}\right\rfloor$ represents the fraction of service life used for component $i$ after its last replacement. For the diesel group the calculation is different because depending on the number of hours, it is done by the relation (19):

$C_{s g} \leq\left(N_{g}+\sum_{y \in T} A_{g}(y)-\frac{D_{g} \times T}{d \vartheta_{g}}\right) \times c_{i_{g}}$

\section{Simulation of the hybrid system:-}

The optimal sizing model presented is now used with the manufacturers' technical data sheets to implement the algorithm using computer tools. To simulate the hybrid system, we used Python language using the Spyder interpreter (ANACONDA.ORG, 2018) and the PuLP library for constraint resolution.

\section{Presentation of the IDE Spyder:-}

Spyder (named Pydee in its first versions) is a development environment for Python. Free (MIT license) and crossplatform (Windows, Mac OS, GNU/Linux), it was created and developed by Pierre Raybaut in 2008 (CAN H. and al., 2012). Spyder is maintained, since 2012 , by a community of developers who have in common that they belong to the scientific Python community.

In comparison with other IDE (Integrated Development Environment) for scientific development, Spyder has a unique set of cross-platform, open-source features, written in Python and available under a non-copyleft license. Spyder is extensible with plugins, includes support for interactive tools for data inspection and incorporates Python code-specific quality assurance and introspection tools, such as Pyflakes, Pylint and Rope.

The IDE Spyder integrates many libraries for scientific use: Matplotlib, NumPy, SciPy, IPython and PuLP. It is the latter that we used for the optimization of the sizing whose objective function and constraints have been detailed previously.

\section{Presentation of the PuLP library:-}

PuLP is a library for the Python programming language that describes mathematical programs by providing objects that can represent optimization problems and decision variables. Easily deployed on any system that has a Python interpreter because it is not dependent on any other software package, this library can be easily extended to additional solvers and is very useful for projects that require linear optimization capabilities.

The PuLP library has many mathematical solvers and has been designed to solve many optimization problems by reducing them to linear functions with integer, real, boolean or mixed variables. It then fits well with the optimization problem posed and performs mathematical operations that other solvers do, such as CPLEX and Gurobi, which are not free.

\section{ILP resolution flowchart:-}

The most commonly used methods or algorithms in ILP resolution (LIBERTI L. and RUSLAN S., 2006; FEDDAOUI Omar, 2014) are :

1. the Gomory slice algorithm or secant plane method which consists in adding constraints to the pre-established problem and which depend on their structure,

2. the Branch and Bound method, which consists in splitting the solution domain into feasible regions bounded by borders aligned on integers: this separates the domains, and evaluates which region to explore first,

3. the method that combines the last two (Branch and Cut),

4. the Knapsack algorithm (backpack) used to solve problems with logical conditions whose decision variables are Boolean ( 0 or 1$)$. 
Figure 5 shows the flowchart for solving the problem of optimizing the sizing of the hybrid plant.

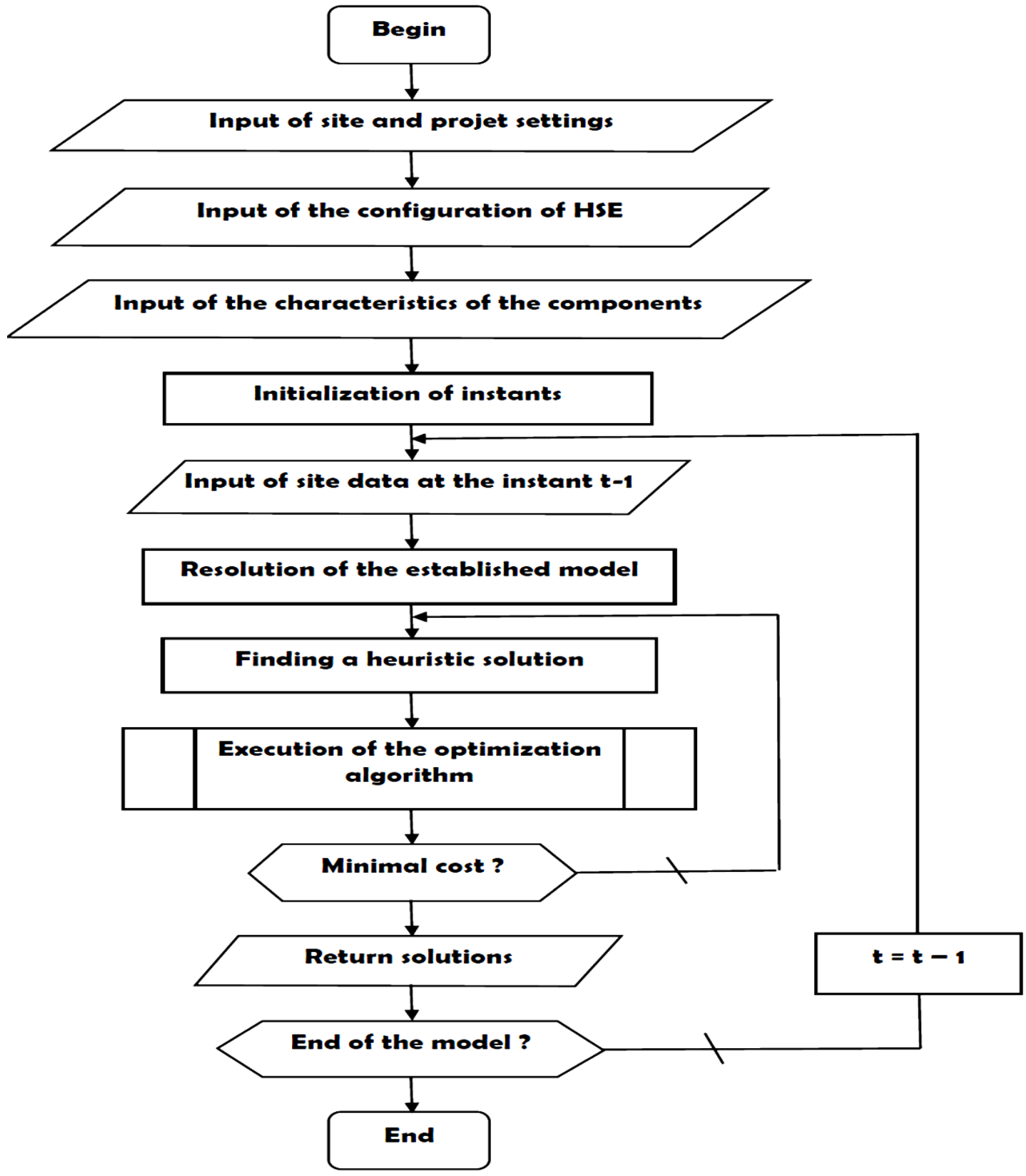

Figure 5:-the ILP Flowchart

Presentation of the selected isolated site:-

The sizing was carried out for a locality near the city of Lomé in Togo with 100 households with five inhabitants per household excluding cooking and heating. The consumption profile of a household (working day and weekend) is shown in Figure 6. 


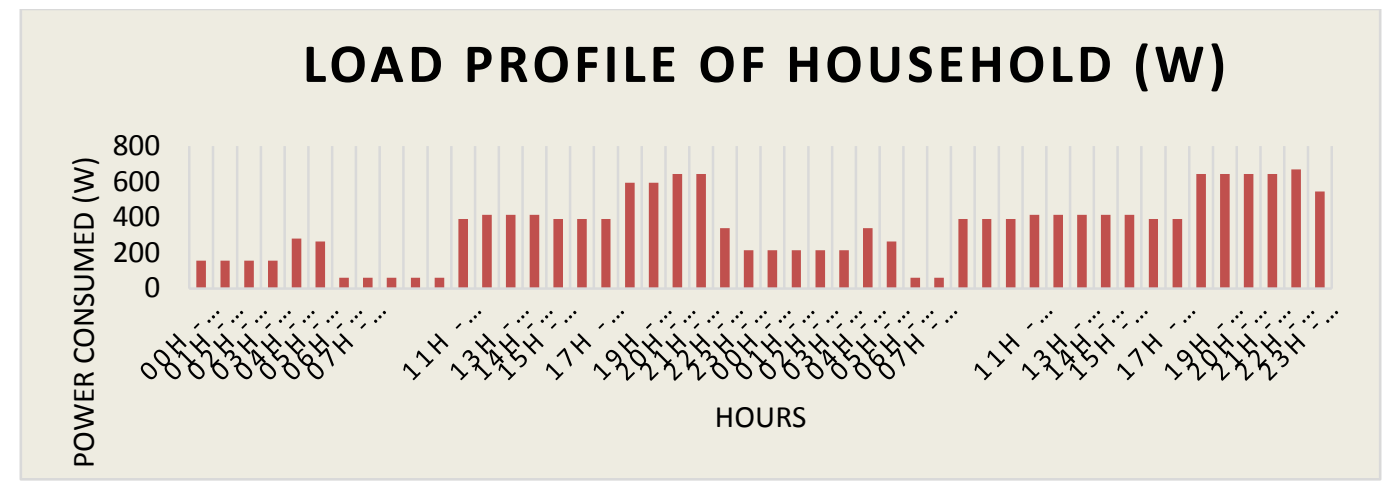

Figure 6:-Household load profile (working day + weekend)

Weather data were collected on the SoDaPro website (Solar radiation Data, 2018). A study of the complementarity of solar and wind potentials has enabled us to judge that the chosen locality is favorable to the installation of a hybrid electrical system.

\section{Sizing results:-}

The sizing was carried out for a total duration of 25 years. The simulation was done over a week and then extended to the rest of the moments. Figure 7 shows the results of the sizing of the hybrid system by the ILP.

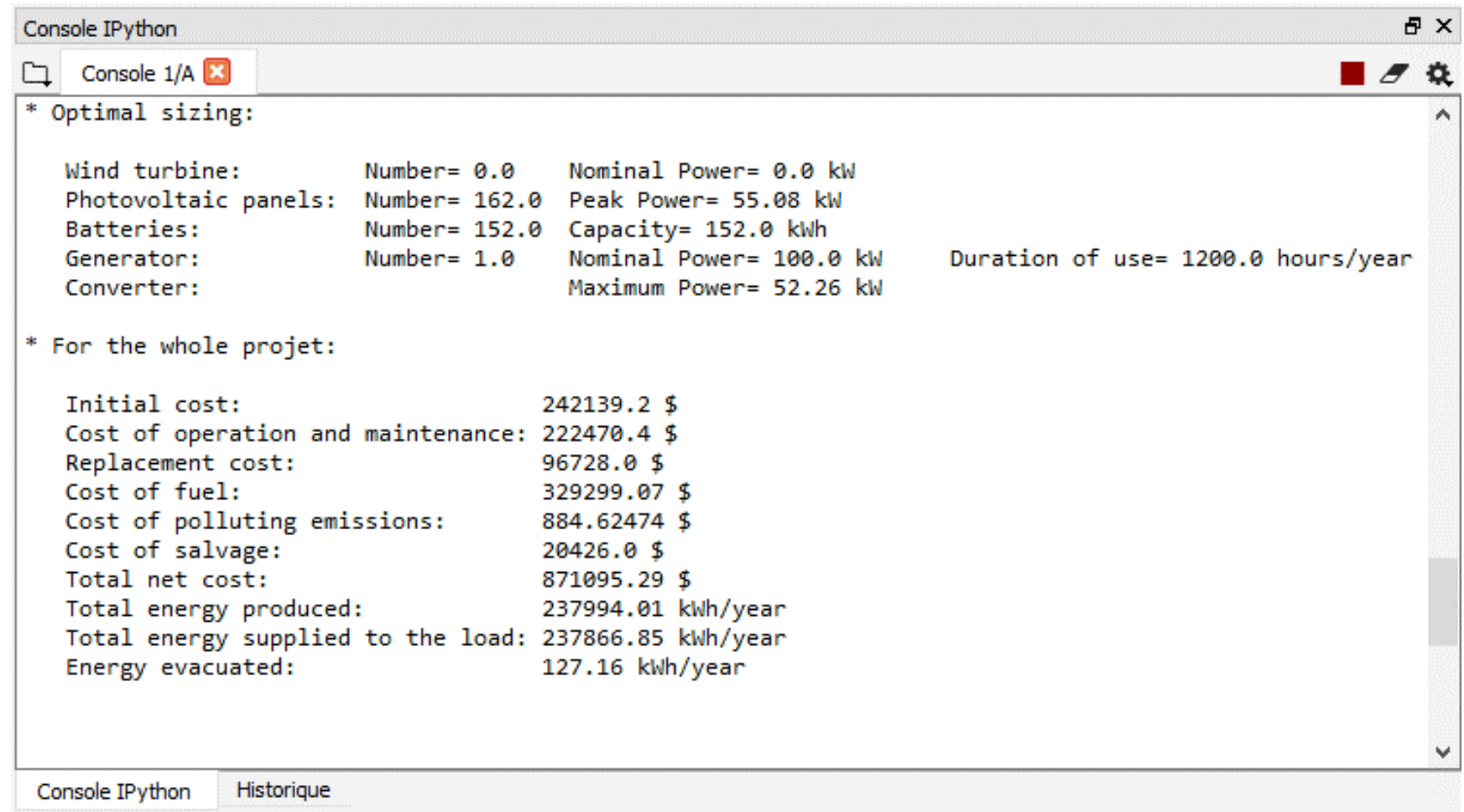

Figure 7:-Sizing results

\section{Analysis of the results:-}

No wind turbine has been retained by the optimal sizing because it is expensive and the wind potential is relatively low. The photovoltaic field and the generator set each share almost half of the energy production. Since the fuel chosen is biodiesel and is inexpensive, the generator set remains the most important component of the hybrid system in both cases, as shown in Figure 8. 


\section{Percentage of energy production of sources}

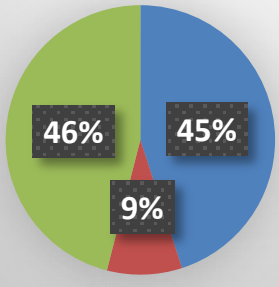

Solar
Battery
Emergency
genrator

\section{Proportion of costs of} system components

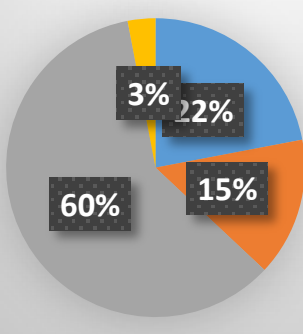

- Solar

Battery

Emergency genrator

Converter

Figure 8:-Technical and economic studies of the ILP results

Comparison of the results with those of the HOMER software:-

HOMER is the reference optimization software for hybrid systems (HOMER, 2017; KANSARA B. and PAREKH B.R, 2011; Seydou Ouedraogo and al., 2015). The same data were simulated to compare the two methods. HOMER's results are given in Figure 9 summarized in Table 1.

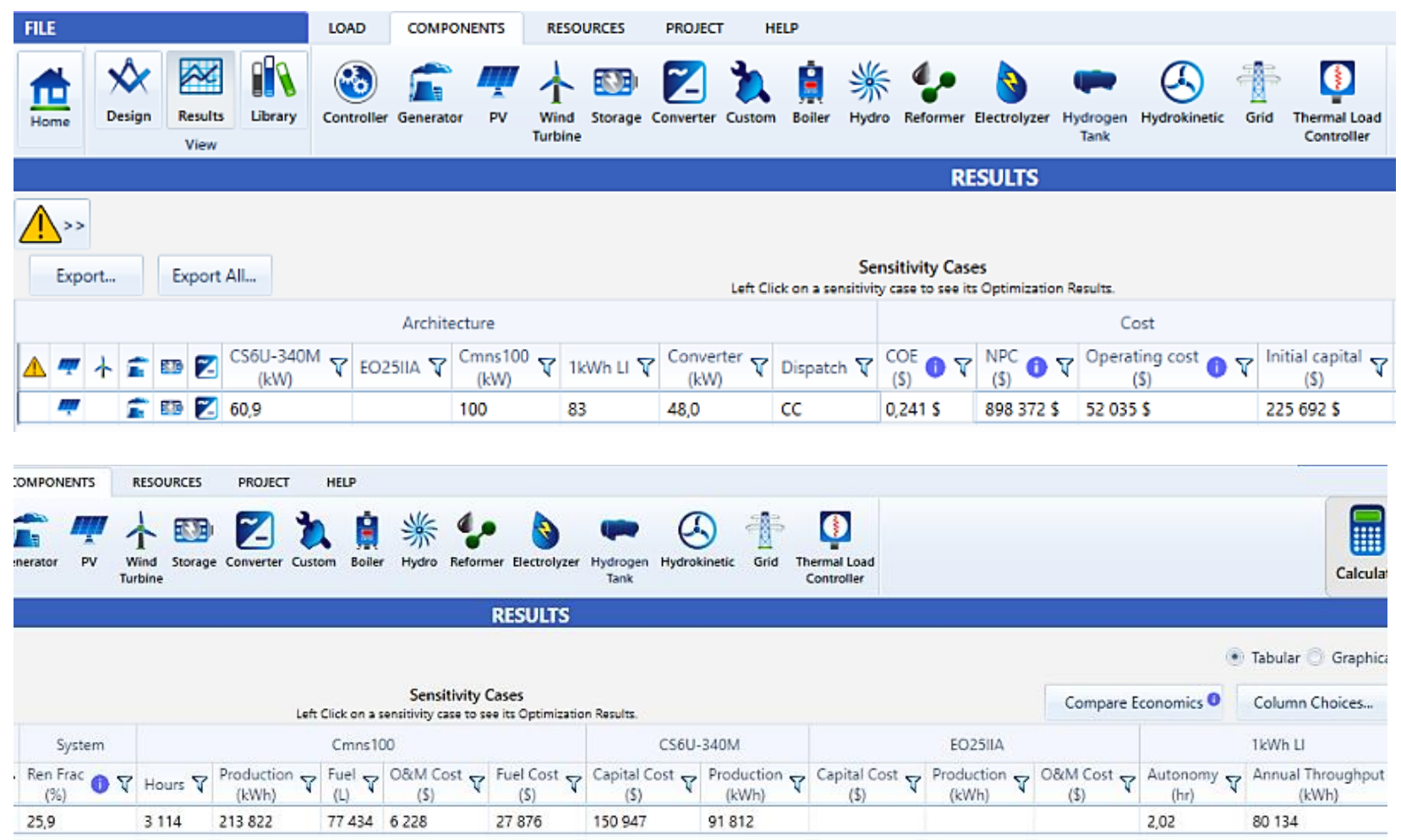

Figure 9:-Result of the optimal sizing by HOMER

Table 1:-Comparative table of simulation results by ILP and HOMER

\begin{tabular}{|l|l|l|l|}
\hline Optimal sizing & ILP & HOMER \\
\hline Quantity and total power or capacity & Wind turbine & 0 & 0 \\
\cline { 2 - 4 } & Photovoltaic panel & $162(55,08 \mathrm{kWp})$ & $180(60,9 \mathrm{kWp})$ \\
\cline { 2 - 4 } & Generator & $1(100 \mathrm{~kW})$ & $1(100 \mathrm{~kW})$ \\
\cline { 2 - 4 } & Battery & $152(152 \mathrm{kWh})$ & $83(83 \mathrm{kWh})$ \\
\cline { 2 - 4 } & Converter & $1(52,26 \mathrm{~kW})$ & $1(48 \mathrm{~kW})$ \\
\hline Produced energy (kWh/year) & Wind turbine & 0 & 0 \\
\cline { 2 - 4 } & Photovoltaic panel & $106836,051(44,89 \%)$ & $91812(30 \%)$ \\
\hline
\end{tabular}




\begin{tabular}{|l|l|l|l|}
\hline \multirow{2}{*}{ Number of replacements } & Generator & $108965,96(45,78 \%)$ & $213822(70 \%)$ \\
\cline { 2 - 4 } & Battery & $22191,99(9,32 \%)$ & Not provided \\
\hline & Photovoltaic panel & 0 & 0 \\
\cline { 2 - 4 } & Generator & 1 & 4 \\
\cline { 2 - 4 } & Battery & 1 & 1 \\
\cline { 2 - 4 } & Converter & 1 & 1 \\
\hline Penetration rate of renewable energy & $44,89 \%$ & $25,90 \%$ \\
\hline Evacuated power (kWh/year) & 127,158 & 8759 \\
\hline Load satisfaction rate (\%) & 100 & 100 \\
\hline
\end{tabular}

The main difference is in the use of generators in energy production. The dimensioning of the batteries is closely linked to this because the more the photovoltaic panels are used, the more consequent the storage device is and vice versa. As the fuel cost is the most significant among those of the project, the one found by HOMER is slightly higher than that of the ILP (Figure 10).

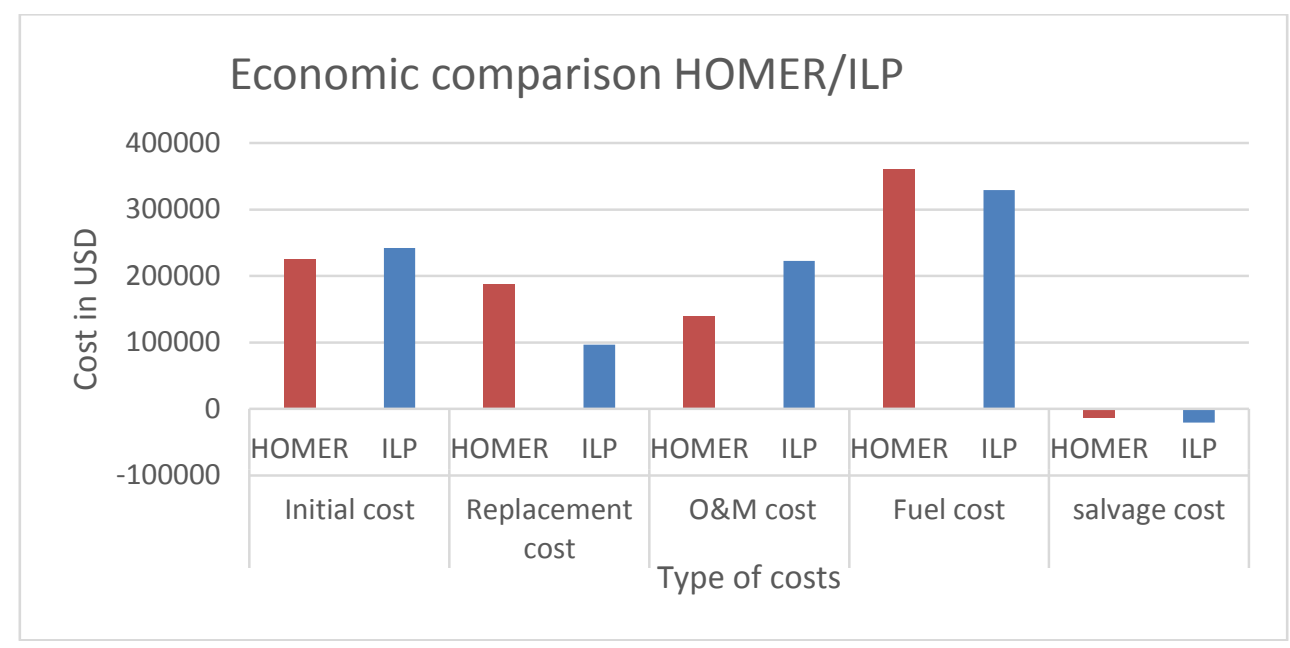

Figure 10:-Economic comparison by cost type

The cost difference between the sizing by the ILP and that of the HOMER software was at the generator set level, more precisely at the fuel cost. The initial costs are relatively identical. There is a certain complementarity between maintenance costs and replacement costs. Indeed, the first is high for ILP and low for HOMER and vice versa in the second case. The grouped costs by component indicated by the two methods are similar except for the cost of the generator set, which we could have expected given the operating time and the energy share of this source in both optimization methods.

\section{Conclusion:-}

From comparative studies of the two sizing optimization methods, we can affirm that the linear integer programming method is effective. With a lower total project cost than HOMER software, this method has significantly reduced the economic weight, ecological impact and dependence of hybrid energy systems for autonomous production of generators. The second advantage of the ILP is its ability to find at each moment considered by the simulation, the most appropriate distribution of the different sources to satisfy the demand at that precise moment. A data mining algorithm in the rest of our future work will make it possible to identify the strategy for distributing the energy sources to be installed by an intelligent controller who will be responsible for choosing the sources to be combined at any time according to certain parameters.

\section{References:-}

1. ANACONDA.ORG, Scientific PYthon Development EnviRonment, 2018 Anaconda, Inc. available on the website https://pythonhosted.org/spyder/ consulted on 26 July 2018.

2. AZIB T., BLEICHNER N., CESCHIA A., TROMPE A., MATHEVET B. and LAROUCI C., Adaptive Control of Hybrid Photovoltaic Generator for Onboard Automotive Application, 2016 International Conference on 
Electrical Systems for Aircraft, Railway, Ship Propulsion and Road Vehicles \& International Transportation Electrification Conference (ESARS-ITEC), Toulouse, pp. 1 - 6, 2-4 Nov. 2016.

3. BARBIER T., Optimization of the strategy and sizing of hybrid wind, diesel and battery systems for isolated sites, Master's thesis, University of Montreal, Sep 2013.

4. BOUHARCHOUCHE A. et al., Conception and realization of a software for the sizing of a hybrid wind energy system, The Renewable Energy Review, Vol. 17 (2014) 359 - 376, September 2014.Vol. 17 N³ (2014) 359 376, September 2014.

5. KODJO K. M., Connexionist approach for modelling and optimizing the performance of a wind turbine generator, unique doctoral thesis in engineering sciences from the University of Lomé, 2005

6. BOUHARCHOUCHE A., BERKOUK E. M. and GHENNAM T., Control and Energy Management of a Grid Connected Hybrid Energy System PV-Wind with Battery Energy Storage for Residential Applications, Eighth International Conference and Exhibition on Ecological Vehicles and Renewable Energies, EVER'13, MonteCarlo, Monaco, March 27-30, 2013

7. CAN H., ICKILLI D. and PARLAK K. S. “A New Numerical Solution Approach for the Real-Time Modeling of Photovoltaic Panels ", Power and Energy Engineering Conference Asia-Pacific, pp. 1-4, March 2012.

8. ENGELAND K., BORGA M., CREUTIN J., and FRANÇOIS B., Space-time variability of climate variables and intermittent renewable electricity production - A review, Renewable Sustainable Energy Review, DOI: 10.1016/j.rser.2017.05.046, Vol. 79, pp. 600-617

9. FEDDAOUI Omar, Contribution to the Study of Hybrid Generation Systems: Application to Renewable Energies, Magister's Thesis, University of Souk -Ahras - 2013-2014, Algeria.

10. HOMER energy software for microgrid and distributed generation power system design and optimization. https://www.homerenergy.com. Consulted on 10/12/2017.

11. HOSSAIN J., SAKIB N., HOSSAIN E., and BAYINDIR R., Modelling and Simulation of Solar Plant and Storage System: A Step to microgrid Technology, International Journal of Renewable Energy Research, vol. 7, no. 2 (2017), pp. 723-737.

12. JACOB T. and ARUN S., Modeling of Hybrid Wind and Photovoltaic Energy System using a New Converter Topology, Electrical and Electronics Engineering: An International Journal (EEEIJ) Vol.1, No.2, August 2012.

13. JIANG L.L., NAYANASIRI D.R., MASKELL D. L. and VILATHGAMUWA D.M., A simple and efficient hybrid maximum power point tracking method for PV systems under partially shaded condition, IECON 2013 39th Annual Conference of the IEEE Industrial Electronics Society, Vienna, pp. 1513 - 1518, 2013.

14. KANSARA B.and PAREKH B.R., Modelling and Simulation of Distributed Generation, System Using HOMER Software, International Conference on Recent Advancements in Electrical, Electronics and Control Engineering, 2011.

15. KASERA J., CHAPLOT A. and MAHERCHANDANI J. K., Modeling and Simulation of Wind- PV Hybrid Power System using MATLAB/Simulink, IEEE Students' Conference on Electrical, Electronics and Computer Science, 2012.

16. KIM S.T., BAE S., KANG Y.C.and PARK J.W., Energy Management Based on the Photovoltaic HPCS With an Energy Storage Device, in IEEE Transactions on Industrial Electronics, Vol. 62, N7, pp. 4608 - 4617, 2015.

17. LIBERTI L., RUSLAN S., "Introduction to Linear Programming in Integer Numbers", LIX, Ecole Polytechnique, December 2006.

18. NGAN M. S. and TAN C. W., Assessment of Economic Viability for PV / wind/ diesel Real-Time Modeling of Photovoltaic Panels, Power and Energy Engineering Conference Asia-Pacific, pp. 1-4, March 2012.

19. REHMAN S. M., MAHBUB Alam, MEYER J.P. and AL-HADHRAMI L. M., "Feasibility study of a WindPV-Diesel Hybrid Power System for a village ’, Renewable Energy 38,pp. 258-268,2012.

20. Seydou Ouedraogo, Ayité Sénah Akoda Ajavon, Mawugno Koffi Kodjo and Adekunlé Akim Salami, Optimality sizing of hybrid electrical power plant composed of photovoltaic generator, wind generator and biogas generator, Research Journal of Engineering Sciences Vol. 7(11), 20-29, December 2018

21. Solar radiation Data (SoDa), SoDa web services available on the website http://www.soda-pro.com consulted on 26 July 2018.

22. UMUHOZA J., ZHANG Y., ZHAO S. and MANTOOTH H. A., 'An adaptive control strategy for power balance and the intermittency mitigation in battery-PV energy system at residential DC microgrid level', 2017 IEEE Applied Power Electronics Conference and Exposition (APEC), Tampa, FL, USA, pp. 1341 - 1345, 2017. 